\title{
S. Pneumoniae Infection Associated with a Hemolytic Uremic Syndrome in an Adult Patient: A Case Report
}

\author{
Esteban-Zubero $\mathrm{E}^{*}$, Daccach-Navarro $\mathrm{MF}^{2}$, Alatorre-Jiménez $\mathrm{MA}^{3}$, Marín-Medina $\mathrm{A}^{4}$, Onyechi $\mathrm{EA}^{5}$, \\ Pola-Bandrés $\mathrm{G}^{6}$, Villeda-González $\mathrm{R}^{7}$, López-García $\mathrm{CA}^{8}$ and Gómez-Ramos $\mathrm{JJ}^{9}$
}

${ }^{1}$ Medical Doctor, Emergency Department, Hospital San Pedro, Logroño, Spain

${ }^{2}$ Primary Care Resident, Cascajos Health Center, Logroño, Spain

${ }^{3}$ Department of Pediatrics, State University of New York Downstate Medical Center, USA

${ }^{4}$ Department of Genetics, University of Guadalajara, Guadalajara, Mexico

${ }^{5}$ Family Medicine Department, Limi Hospital and Maternity, Abuja, Nigeria

${ }^{6}$ Department of Surgery, Hospital Clínico Universitario Lozano Blesa, Zaragoza, Spain

${ }^{7}$ Research Department, Asociación Mexicana de Atrofia Muscular Espinal (AMAME), Guadalajara, Mexico

${ }^{8}$ Mission Regional Medical Center, Mission Texas, USA

${ }^{9}$ Medical Doctor, Emergency Department, Instituto Mexicano de la Seguridad Social Hospital, Mexico

*Corresponding author: Esteban-Zubero E, Emergency Department of Hospital San Pedro, Calle Piqueras 98, Logroño, Spain 26006, Tel: +34654123994,+34941298000, E-mail: eezubero@gmail.com, eestebanz@riojasalud.es

Citation: Esteban-Zubero E, Daccach-Navarro MF, Alatorre-Jiménez MA, Marín-Medina A, Onyechi EA, et al. (2018) S. Pneumoniae Infection Associated with a Hemolytic Uremic Syndrome in an Adult Patient: A Case Report. J Case Rep Stud 6(2): 204. doi: 10.15744/2348-9820.6.204

Received Date: January 08, 2018 Accepted Date: April 25, 2018 Published Date: April 27, 2018

\begin{abstract}
Hemolytic uremic syndrome (HUS) is a rare but severe entity characterized by the triad of acute kidney injury, microangiopathic hemolytic anemia, and thrombocytopenia. This disease is frequently observed in children after a diarrhea process secondary to Escherichia coli O157: H7. However, other disturbs may generate this disease, including pneumonia secondary to S. pneumoniae, which represents around 5\% of all HUS cases. This type of HUS has demonstrated an increase in incidence in the population recently.

We report a case of an 83 -years-old with hypothermia $\left(33^{\circ} \mathrm{C}\right)$ after being found at home on the floor. The blood revealed a severe anemia (hemoglobin $4.8 \mathrm{~g} / \mathrm{dL}$; hematocrit 15.3\%; red blood cell count $1.54 \times 1012 / \mathrm{L}$ ), hemolysis (lactate dehydrogenase $615 \mathrm{U} / \mathrm{L} ;$ potassium $5.8 \mathrm{mmol} / \mathrm{L}$ ), acute renal failure (creatinine $4.22 \mathrm{mg} / \mathrm{dL}$; urea $174 \mathrm{mg} / \mathrm{dL}$ ), and thrombocytopenia (platelet count $57 \times 109 / \mathrm{L}$ ). The peripheral smear was notable for toxic granulation in the neutrophils, large platelets, target cells, microspherocytes, and schistocytes. A chest X-ray showed right-sided lower lobe pneumonia, isolating S. pneumoniae infection in the urine culture. Due to the critical situation of the patient, intense fluid therapy, vasoactive drugs (dopamine), and temperature control by physical measurements was initiated as treatment. The evolution of the patient after the beginning of the treatment was torpid, resulting in a cardiorespiratory arrest and death.
\end{abstract}

The prognosis of patients with pneumococcal-HUS is strongly dependent on the effectiveness of antibiotic therapy as well as supportive intensive care (including steroids pulse therapy). Early recognition and prompt initiation of antibiotics with supportive intensive care may improve the outcome.

Keywords: DHemolytic uremic syndrome; Pneumonia; Adult patient; Streptococcus pneumoniae

List of abbreviations: HUS: Hemolytic uremic syndrome

\section{Introduction}

Hemolytic uremic syndrome (HUS) is a rare but severe entity characterized by the triad of acute kidney injury, microangiopathic hemolytic anemia, and thrombocytopenia [1]. This disease is most frequently observed in children and, in $90 \%$ of the cases, is preceded by a diarrhea prodrome, typically secondary to Escherichia coli O157: H7 [1]. This subtype of HUS is classified in the same group as typical HUS. In this group are also observed HUS secondary to solid organ transplantation, autoimmune diseases, drugs, pre-existing nephropathy, and others infections, including pneumonia secondary to $S$. pneumoniae. The last one represents around $5 \%$ of all HUS cases; however, the incidence is thought to be increased recently [2,3]. On the other hand, atypical HUS that 
represents less than 5\%, is defined as HUS without coexisting disease or condition, or specific infection [3].

We report a case of an 83-years-old patient affected by HUS secondary to S.pneumoniae. To our knowledge, this is an extremely rare entity, with very few cases reported in the literature.

\section{Case report}

An 83-years-old Caucasian male patient with a personal history of high blood pressure was accepted in the Emergency Department with hypothermia $\left(33^{\circ} \mathrm{C}\right)$. The patient was found at his home on the floor. It was unknown if there has been a loss of consciousness during the event.

During physical exploration, the patient did not refer any pain. At the arrival to the emergency department, the examination showed a blood pressure was $88 / 35 \mathrm{mmHg}$, temperature $33.5^{\circ} \mathrm{C}$, and oxygen saturation $90 \%$ while breathing ambient air. On physical examination, the patient was tachypneic, and hypoventilation on the right lung base was discovered. He was noted to be pale and mildly dehydrated. On neurological examination, the patient was observed in disturbance and disorientation.

During his admission, a blood test was performed revealing a severe anemia (hemoglobin $4.8 \mathrm{~g} / \mathrm{dL}$; hematocrit $15.3 \%$; red blood cell count $1.54 \times 1012 / \mathrm{L}$ ), hemolysis (lactate dehydrogenase $615 \mathrm{U} / \mathrm{L}$; potassium $5.8 \mathrm{mmol} / \mathrm{L}$ ), acute renal failure (creatinine 4.22 $\mathrm{mg} / \mathrm{dL}$; urea $174 \mathrm{mg} / \mathrm{dL}$ ), thrombocytopenia (platelet count $57 \times 109 / \mathrm{L}$ ), total bilirubin $3.5 \mathrm{mg} / \mathrm{dL}$, aspartate aminotransferase 243 $\mathrm{U} / \mathrm{L}$, alanine aminotransferase $110 \mathrm{U} / \mathrm{L}$, Urinalysis showed proteinuria $(50 \mathrm{mg} / \mathrm{dL}$ ) and hematuria (hemoglobin $0.03 \mathrm{mg} / \mathrm{dL}$ ). Urinary excretion of sodium was $14 \mathrm{mmol} / \mathrm{L}$. The peripheral smear was notable for toxic granulation in the neutrophils, large platelets, target cells, microspherocytes, and schistocytes. A chest X-ray showed right-sided lower lobe pneumonia (Figure 1). Due to the renal failure, indication for an abdominal ultrasound was done without discovering any disturbance at renal level.

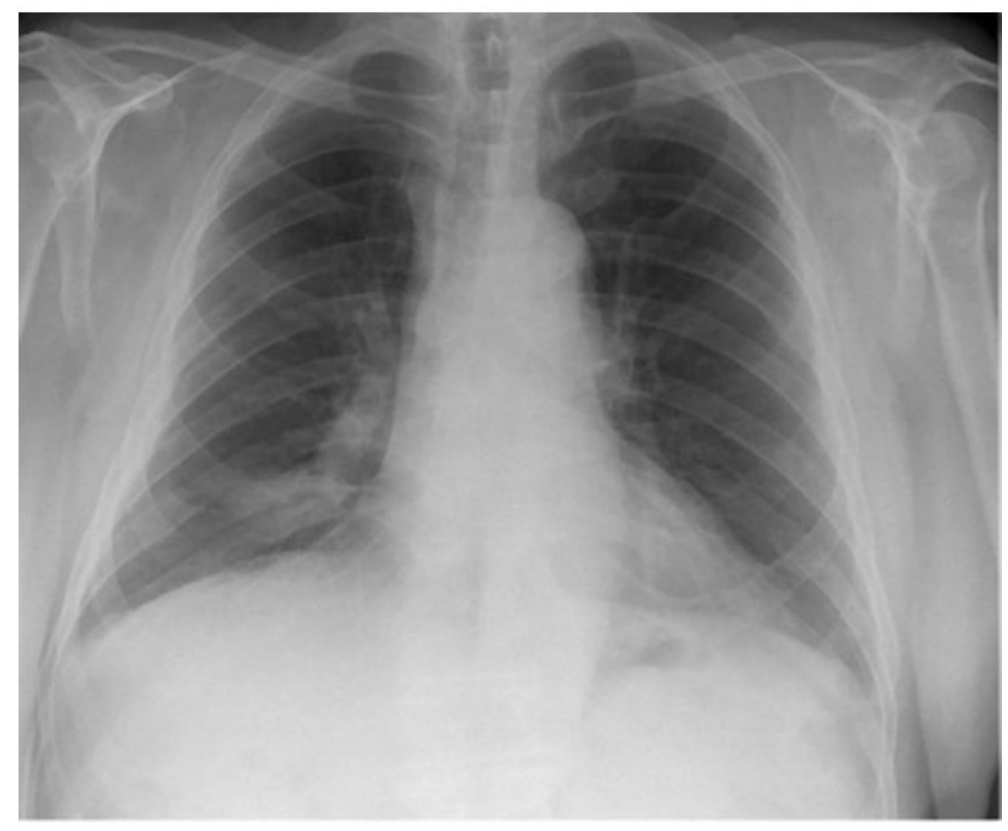

Figure 1: Chest X-ray showing right side lower lobe pneumonia

Due to the critical situation of the patient, treatment was started with intense fluid therapy, vasoactive drugs (dopamine), and temperature control by physical methods. The evolution of the patient after the beginning of the treatment was torpid, resulting in a cardiorespiratory arrest and progressed to death.

Post-mortem results revealed an S. pneumoniae infection isolated in the urine culture.

\section{Discussion}

The pathophysiology of all forms of HUS is the presence of endothelial cell lesions in the microvasculature of the kidney and, less frequently, of other organs [4]. This entity typically presents in children after a diarrhea process, generally secondary to Escherichia coli O157: H7 [1]. However, Pneumococcal associated HUS is a rare, but potentially fatal disease that may complicate pneumonia or, less frequently, meningitis caused by S. pneumoniae [5]. It occurs mainly in children under the age of two, while in adults, it is scarce [6]. Nevertheless, some authors suggested that this entity may be underdiagnosed [7].

Pathogenesis of HUS secondary to pneumonia is caused by the amount of neuraminidase that is generated by $S$. pneumoniae to cleave $\mathrm{N}$-acetylneuraminic acid from the glycoprotein on the cell membrane of erythrocytes, platelets, and glomerular cells [8]. This feature exposes the Thomsen-Friedenreich antigen (T-antigen), which can then react with anti-T IgM antibodies of human plasma. As a result of this antigen-antibody reaction, a poly-agglutination of red blood cells occurs, generating a positive Coombs' 
test (HUS usually show a negative Coombs' test) [9]. Also, in the acute phase, patients had decreased levels of C3 and C4 and reduce the residual activity of the classical as well as alternative pathways of complement activation, indicating severe complement consumption [6].

In our patient, the diagnosis of HUS secondary to $S$. pneumoniae infection was based on the classical triad of nonimmune microangiopathic hemolytic anemia, thrombocytopenia, and acute renal failure, in the absence of a diarrheal prodrome. Also, the diagnosis was confirmed post-mortem due to the isolation of $S$. pneumoniae in the urine culture.

The prognosis of patients with pneumococcal-HUS is strongly dependent on the effectiveness of antibiotic therapy [10]. Because of that, early recognition and prompt initiation of antibiotics with supportive intensive care improve the outcomes. The main antibiotics used are amoxicillin or third-generation cephalosporin in case of meningitis [10]. While plasma either infused or exchanged is useful in HUS, in pneumococcal-HUS is contraindicated due that plasma contains anti-Thomsen-Friedenreich antibodies, which might enhance agglutination of Thomsen-Friedenreich-anti-Thomsen- Friedenreich and worsen the HUS course. Because of that, these patients should be treated only with antibiotics and washed red cells [11]. Also, some authors suggested that methylprednisolone pulse therapy would be useful in early stages due to the systemic release of proinflammatory cytokines that occurs in pneumococcal-HUS [12].

For our knowledge, few adult cases of pneumococcal-HUS have been reported [13-17]. In the literature, patients with splenectomy have an increased incidence of pneumococcal-HUS. Also, the early treatment with antibiotics as well as the steroids pulse therapy improves the outcome $[1,4,5]$. In our case, the belated recognition of the disease, as well as the long-term evolution, led to the death of this patient.

\section{Conclusion}

HUS is a rare, but severe most frequently observed in children. In $90 \%$ of the cases, is preceded by a diarrhea prodrome, typically secondary to Escherichia coli O157: H7. However, HUS may also be produced secondary to other diseases including pneumonia secondary to S. pneumoniae, which represents around 5\% of all HUS cases. The early recognition and prompt initiation of antibiotics with supportive intensive care (including steroids pulse therapy) in pneumococcal-HUS improve the prognosis.

\section{References}

1. Fakhouri F, Zuber J, Frémeaux-Bacchi V, Loirat C (2017) Haemolytic uraemic syndrome. Lancet 390: 681-96.

2. Weintraub L, Ahluwalia M, Dogra S, Uehlinger J, Skversky A, et al. (2014) Management of streptococcal pneumoniae-induced hemolytic uremic syndrome: a case report. Clin Nephrol Case Stud 2: 9-17.

3. Loirat C, Fakhouri F, Ariceta G, Besbas N, Bitzan M, et al. (2016) An international consensus approach to the management of atypical hemolytic uremic syndromein children. Pediatr Nephrol 31: 15-39.

4. Webster K, Schnitzler E (2014) Hemolytic uremic syndrome. Handb Clin Neurol 120: 1113-23.

5. Mele C, Remuzzi G, Noris M (2014) Hemolytic uremic syndrome. Semin Immunopathol 36: 399-420.

6. Szilagyi A, Kiss N, Bereczki C, Talosi G, Racz K, et al. (2013) The role of complement in Streptococcus pneumoniae-associated haemolytic uraemic syndrome. Nephrol Dial Transplant 28: 2237-45.

7. Waters AM, Kerecuk L, Luk D, Haq MR, Fitzpatrick MM, et al. (2007) Hemolytic uremic síndrome associated with invasive pneumococcal disease: the United kingdom experience. J Pediatr 151: 140-4.

8. Cochran JB, Panzarino VM, Maes LY, Tecklenburg FW (2004) Pneumococcus-induced T-antigen activation in hemolytic uremic syndrome and anemia. Pediatr Nephrol 19: 317-21.

9. Eder AF, Manno CS (2001) Does red-cell T activation matter? Br J Haematol 114: 25-30.

10. Banerjee S (2009) Hemolytic uremic syndrome. Indian Pediatr 46: 1075-84.

11. McGraw ME, Lendon M, Stevens RF, Postlethwaite RJ, Taylor CM (1989) Haemolytic uraemic syndrome and the Thomsen Friedenreich antigen. Pediatr Nephrol 3: 135-9.

12. Tsuruga K, Oki E, Yashiro T, Fujita H, Shinagawa T, et al. (2010) Anti-inflammatory treatment for post-diarrhoeal haemolytic-uraemic syndrome with central nervous system involvement. Nephrology (Carlton) 15: 659-60.

13. von Eyben FE, Szpirt W (1985) Pneumococcal sepsis with hemolyticuremic syndrome in the adult. Nephron 40: 501-2.

14. Myers KA, Marrie TJ (1993) Thrombotic microangiopathy associated with Streptococcus pneumoniae bacteremia: case report and review. Clin Infect Dis 17: $1037-40$.

15. Ohlmann D, Hamann GF, Hassler M, Schimrigk K (1996) Involvement of the central nervous system in haemolytic uremic syndrome and thromboticthrombocytopenic purpura. Nervenarzt 67: 880-2.

16. Reynolds HE, Espinoza RM, Mönckeberg FG, Graf SJ (2002) Síndrome hemolítico-urémico y Streptococo pneumoniae: Report of one case. Rev Méd Chile 130: $677-80$.

17. Maki N, Komatsuda A, Ohtani H, Kuroki J, Nishinari T, et al. (2012) Streptococcus pneumoniae-associated hemolytic uremic syndrome in a splenectomized adult patient. Intern Med 51: 2001-5. 


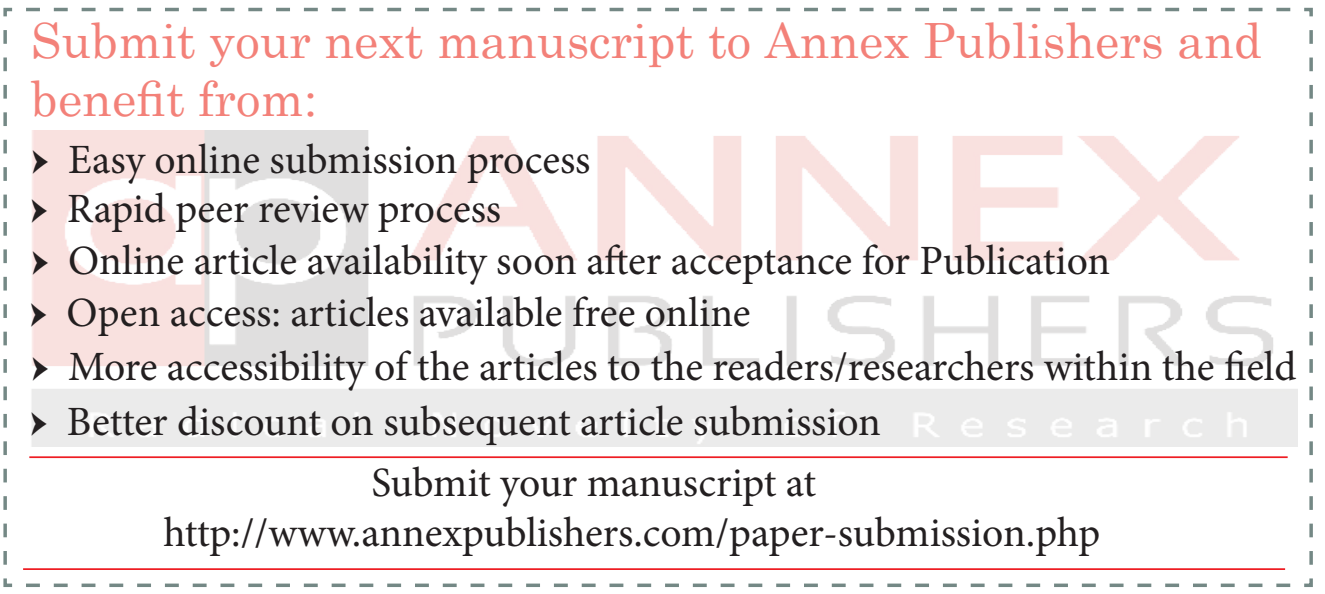

